\title{
Genome sequence and comparative genomic analysis of a clinically important strain CD11-4 of Janibacter melonis isolated from celiac disease patient
}

\author{
Atul Munish Chander ${ }^{1,3}$, Rakesh Kochhar ${ }^{2}$, Devinder Kumar Dhawan', Sanjay Kumar Bhadada ${ }^{3^{*}}$ \\ and Shanmugam Mayilraj ${ }^{4^{*}+}$
}

\begin{abstract}
Background: Janibacter melonis and other member of this genus are known to cause bacteremia and serious clinical comorbidities, but there is no study reporting about pathogenicity attributes of J. melonis. Janibacter terrae is known to cause lethal infection. Reporting the genome of J. melonis CD11-4 and comparative genomics with other members of genus has provided some novel insights that can enable us to understand the mechanisms responsible for its pathogenicity in humans.

Results: Comparative genomic analysis by Rapid Annotation Server and Technology revealed the presence of similar virulence determinant genes in both J. terrae NBRC $107853^{\top}$ and J. melonis CD11-4. Like J. terrae NBRC $107853^{\top}$, J. melonis CD1 1-4 contained two genes responsible for resistance against $\beta$-lactam class of antibiotics and two genes for resistance against fluoroquinolones. Interestingly, J. melonis CD11-4 contained a unique gene coding for multidrug resistance efflux pumps unlike all other members of this genus. It also contained two genes involved in Toxin-antitoxin Systems that were absent in J. terrae NBRC $107853^{\top}$ but were present in some other members of genus.

Conclusions: Genome annotations of J. melonis CD11-4 revealed that it contained similar or more virulence repertoire like J. terrae NBRC $107853^{\top}$. Like other gut pathogens, J. melonis possesses key virulence determinant genes for antibiotic resistance, invasion, adhesion, biofilm formation, iron acquisition and to cope with stress response, thereby indicating that strain J. melonis CD11-4 could be a gut pathogen.
\end{abstract}

Keywords: Genome sequencing, Janibacter melonis, Virulence, Clinical pathogen

\section{Background}

The genus Janibacter belongs to phylum Actinobacteria and family Intrasporangiaceae [1], that are non-spore forming, non-motile, aerobic, oxidase variable, and catalase-positive Gram-positive organisms. Colonies formed

\footnotetext{
*Correspondence: bhadadask@rediffmail.com; mayil@imtech.res.in †Sanjay Kumar Bhadada and Shanmugam Mayilraj are joint corresponding authors

${ }^{3}$ Department of Endocrinology, Postgraduate Institute of Medical Education and Research, Chandigarh, India

${ }^{4}$ Microbial Type Culture Collection and Gene Bank (MTCC), CSIR-Institute of Microbial Technology, Chandigarh 160036, India

Full list of author information is available at the end of the article
}

by these bacteria are smooth, circular, convex, and vary in color from white to yellow [2]. Strain CM2104 ${ }^{\mathrm{T}}$ was proposed as novel species Janibacter melonis in 2004, which was isolated from a spoiled oriental melon in Korea [3]. Elsayed et al. [4], for the first time isolated this microbe from blood (a clinical source) of a patient who presented with an acute onset of low-grade fever, rightsided facial swelling with pain, headache, and erythema after being bitten by an insect on his cheek. On the first day of illness, the insect stinger was completely removed by using a kitchen knife. Intravenous antibiotic therapy with cefazolin ( $2 \mathrm{~g}$ every $8 \mathrm{~h})$ had improved the patient's symptoms. 
Janibacter terrae, another species of the genus, were reported recently to cause bacteremia in humans, and antibiotic treatments had improved the condition of 2 patients, while 2 other immune-compromised patients died due to infection [2]. In this study, for the first time, genome sequence of a clinical isolate belonging to the genus Janibacter is reported, which is isolated from duodenal mucosa of a celiac disease (CD) patient.

Earlier, we have reported that $\mathrm{CD}$ co-occurs with a number of diseases [5-8], whereas some other studies reported that microbes/infections modulate the disease presentations in CD [9-13]. By sequencing the genomes of microbes, we attempted to identify the genetic basis of pathogenicity, particularly microbial virulence and its probable role in CD $[14,15]$. Infections play important in autoimmune diseases and $C D[12,16]$, but the prevalence and role of $J$. melonis in CD is not known so far; thus our work will highlights this organism as a probable pathogen. Therefore, infection caused due to J. melonis may need treatments to improve the clinical condition of the patients.

Reporting genome sequence and comparative genomics of J. melonis CD11-4 with other members of genus has provided some important insights. This report may enable us to understand the genetic mechanisms responsible for its pathogenicity in human diseases.

\section{Methods}

\section{Bacterial strain culture and characterization}

Strain CD11-4 was recovered from duodenal mucosa of a CD patient who was tTG IgA-antibody (Ab) positive $(>100 \mathrm{U} / \mathrm{ml})$ presented with gastrointestinal symptoms including abdominal pain and painful defecation. It was proposed as strain CD11-4 of J. melonis. The tissue samples from duodenal mucosa were recovered during endoscopy at the Postgraduate Institute of Medical Education and Research, Chandigarh, India. The samples were used for characterisation of culturable microbes in the patient. After homogenizing in sterile phosphate saline (PBS), the samples were centrifuged at $4000 \mathrm{rpm}$ for 2 min to remove debris. The supernatant was recovered and serially diluted with PBS and plated on to tryptic soy agar (TSA; HiMedia, India), incubated at $37^{\circ} \mathrm{C}$ for $36 \mathrm{~h}$. Single colonies appearing on the plate were picked and streaked on TSA plates that were further passaged at least two times to obtain pure colonies. Genomic DNA extraction and amplification were performed as described previously [17].

The strain designated as CD11-4 matched most of the phenotypic features of J. melonis $\mathrm{CM}_{2104^{\mathrm{T}}}$ and CM2110 [3]. Strain CD11-4 was identified as J. melonis by using $16 \mathrm{~S}$ rRNA gene sequencing from the genomic DNA and was confirmed through an analysis of $16 \mathrm{~S}$ rRNA gene retrieved from its whole genome sequence. Gene coding for 16S rRNA has shown that the strain CD11-4 belongs to the genus Janibacter and is most closely related to $J$. melonis CM2104 ${ }^{\mathrm{T}}$ (99.52\% identity; $100 \%$ sequence completeness, 7 bases difference of a total 1446 bases) followed by J. terrae NBRC $107853^{\mathrm{T}}$ (98.42\% identity: $100 \%$ sequence completeness, 22 bases difference of a total 1447 bases), J. anophelis CCUG $49715^{\mathrm{T}}$ (98.48\% identity: $100 \%$ sequence completeness, 22 bases difference of a total 1444 bases) and J. cremeus HR08- $44^{\mathrm{T}}$ (97.99\% identity: $100 \%$ sequence completeness, 29 bases difference of a total 1446 bases).

\section{Genome sequencing, assembly, and gene annotations and comparative genomic analysis}

Genome of the strain was sequenced at C-CAMP (http:// www.ccamp.res.in/) next-generation genomics facility, Bengaluru, India using an Illumina HiSeq $2 \times 100$ platform. Library preparation and sequencing were performed according to methods described previously [16]. The prepared libraries were quantified and then validated for quality by running an aliquot on High Sensitivity Bio analyser Chip, Agilent. De Novo assembly was performed with CLC Genomics Workbench (v8.5.1, CLCbio, Arhus, Denmark). During assembly, word size was set 45 and bubble size was 98. Default setting was used for read filtering and trimming, with a quality score of 0.05 and a maximum ambiguous nucleotides of 2 . For operation "Discard reads below length", the number was set to 15 .

Genome annotation for the strain was performed by using Rapid Annotation Server and Technology (RAST) [17-20]. For comparative genomic analysis, genomes of J. limosus NBRC $16128^{\mathrm{T}}$ (type species of genus), J. terrae NBRC $107853^{\mathrm{T}}$, Janibacter indicus LMG $27493^{\mathrm{T}}$, Janibacter anophelis NBRC $107843^{\mathrm{T}}$, Janibacter hoylei PVAS-1 ${ }^{\mathrm{T}}$, Janibacter corallicola $\mathrm{NBRC} 107790^{\mathrm{T}}$ and Janibacter spp. HTCC 2649 were retrieved from genome database of NCBI and were also annotated by using RAST.

As described previously [16], we identified unique genes, potential pathogenicity determinants, genes involved in metabolic pathways related to virulence, and common genes among three strains J. limosus NBRC $16128^{\mathrm{T}}$ (reference species of the genus), J. terrae NBRC 107853 (another reference strain), and J. melonis CD11-4. J. limosus NBRC $16128^{\mathrm{T}}$ is the type species of the genus and was considered for genomic analysis along with $J$. melonis CD11-4 so that the evolutionary trends could be compared for presence of new/unique genes. J. terrae is the pathogenic isolate reported from the genus Janibacter, and known to be lethal in immunocompromised individuals. Thus, another objective was to identify the common key pathogenic determinant genes in $J$. melonis CD11-4 and J. terrae NBRC $107853^{\mathrm{T}}$. Therefore, 
only J. limosus NBRC $16128^{\mathrm{T}}$ and J. terrae NBRC $107853^{\mathrm{T}}$ were chosen for pathogenomic comparison with J. melonis CD11-4. Genes responsible for multidrug resistance efflux pumps and $\beta$-lactamase (cephalosporin) were reported as unique in J. melonis CD11-4 when comparative analysis was performed in three organisms. To confirm the uniqueness of these genes in the whole genus, rest of the genomes were searched for the above mentioned two genes by using RAST.

BLAST Ring Image Generator (BRIG) software was used to visualize the genome sequence similarity among strain CD11-4 and all other strains of the genus in the form of a map [21].

\section{Results and discussions}

\section{Genome features}

Draft genome of J. melonis strain CD11-4 consisted of $3,196,878$ bp with $G+C$ content of $73 \%$. As per RAST annotations, it had 3064 coding sequences, 311 subsystems, and 49 total RNAs (Table 1). During assembly of the genome in CLC Genomics Workbench (v8.5.1, CLCbio, Arhus, Denmark), the strain was reported to have $12,007,098$ reads. The data was preprocessed to trim and remove low quality sequences and finally a total of $11,823,074$ high quality, vector filtered reads were employed for assembly. The assembled genome contained 7 contigs with N50 contig length of 483,445 bp and the largest contig assembled measured $957,763 \mathrm{bp}$.

\section{Comparative genomics}

To calculate Average Nucleotide Identity (ANI), all the genomes were compared with strain CD11-4 by using ANI calculator [22, 23]. No other genome was available for $J$. melonis in the genome database of NCBI. When genome sequence of $J$. melonis CD11-4 was compared with J. terrae, ANI value had been reported $77.28 \%$. The ANI value was $76.59 \%$ for $J$. limosus, $77.22 \%$ for

Table 1 Genome features of J. melonis CD11-4

\begin{tabular}{ll}
\hline Genome annotations/features & J. melonis strain CD11-4 \\
\hline Accession no & LQZG00000000 \\
Isolation source & Duodenal mucosa of CD patient \\
Size (Mb) & 3.2 \\
Contigs & 7 \\
G + C & 73 \\
tRNA & 46 \\
Other RNA & 3 \\
No. of RNAs & 49 \\
No. of subsystem & 311 \\
Proteins/coding genes & 2936 \\
\hline
\end{tabular}

J. anophelis, $76.57 \%$ for J. corallicola, $77.41 \%$ for J. hoylei, $77.46 \%$ for $J$. indicus, and $74.07 \%$ for J. spp. During the ANI calculations of $J$. melonis CD11-4 versus other genomes, the genome coverage was reported in a range of $26.02-38.03 \%$ for J. melonis and $19.67-37.39 \%$ for the compared genomes.

\section{Virulence, disease and defense}

By using RAST server, comparative genomic analysis was performed among $J$. limosus NBRC $16128^{\mathrm{T}}$, J. terrae strain NBRC $107853^{\mathrm{T}}$, and J. melonis CD11-4. As per classification of protein functions in RAST, category Virulence, disease and defense (VDD) consists of two main sub-categories that include (i) resistance to antibiotics and toxic compounds and (ii) invasion and intracellular resistance. Virulence determinant genes for resistance to antibiotics and toxic compounds have clinical significance, whereas genes belonging to the subcategory invasion and intracellular resistance are other possible cause of infection.

In category VDD, J. terrae NBRC $107853^{\mathrm{T}}$ had 40 genes, whereas J. melonis CD11-4 had 36 genes, and J. limosus NBRC $16128^{\mathrm{T}}$ had 34 genes. Subcategory "Invasion and intracellular resistance", contains 15 genes in strains J. melonis CD11-4 and J. terrae NBRC $107853^{\mathrm{T}}$ whereas 13 genes are in J. limosus NBRC $16128^{\mathrm{T}}$. In subcategory, Resistance to antibiotics and toxic compounds, out of total 28 genes, J. melonis CD11-4 had 26 genes, $J$. terrae NBRC $107853^{\mathrm{T}}$ had 25 genes and J. limosus NBRC $16128^{\mathrm{T}}$ had 21 genes.

Resistance to antibiotics and toxic compounds While comparing J. terrae NBRC $107853^{\mathrm{T}}$ and J. melonis CD114, 4 genes were common in subsystem Arsenic resistance, 2 genes were common in subsystem $\beta$-lactamase, 3 genes were common in subsystem zinc-cadmium resistance, 4 genes were common in subsystem copper homeostasis, and 1 gene was common in subsystem resistance to vancomycin, 4 genes were common in subsystem resistance to fluoroquinolones, 1 gene was common in copper homeostasis, 1 gene was common in subsystem cadmium resistance and 2 genes were common in subsystem mercuric reductase. In subsystem $\beta$-lactamase, like both $J$. terrae NBRC $107853^{\mathrm{T}}$ and J. melonis CD11-4, reference strain J. limosus NBRC $16128^{\mathrm{T}}$ also had similar set of genes but genes coding for $\beta$-lactamase class $C$, other penicillin binding proteins and metal-dependent hydrolases of the $\beta$-lactamase superfamily III were absent in it.

One gene in each subsystem arsenic resistance, $\beta$-lactamase (cephalosporin), and multidrug resistance efflux pumps was unique in J. melonis CD11-4 that may make it a potent drug resistance strain in comparison to other strains of the genus. Interestingly, a unique 
subsystem, multidrug resistance efflux pumps, was present in J. melonis CD11-4 that contained a gene coding for multi antimicrobial extrusion protein $(\mathrm{Na}(+) /$ drug antiporter) belonging to MATE family of MDR efflux pumps (Fig. 1). We reported that this gene is absent in all other members of this genus conferring it's uniqueness over the whole genus. The data supports clinical adaptabilities developed by strains J. melonis CD11-4 and J. terrae NBRC $107853^{\mathrm{T}}$.

The strain CD11-4 had shown resistance only against nitrofurantoin $(300 \mathrm{mcg})$ and sensitivity to all other antibiotics during antibiotic assay performed by using Icosa universal-2 and Icosa pseudo-2 panel (HiMedia, India). Icosa universal-2 panel assay revealed sensitivity of strain CD11-4 for antibiotics namely, amikacin, ampicillin, amoxycillin, cefadroxil, cefoperazone, ceftazidime, ceftriaxone, chlorampheniol, ciprofloxacin, cloxacillin, co-trimoxazole, erythromycin, gentamicin, nalidixic acid, netillin, nitrofurantoin, norfloxacin, penicillin, tobramycin, and vancomycin. When antibiotic assay was performed by using Icosa pseudo-2 panel, strain CD11-4 has shown sensitivity to other additional antibiotics gentamicin, imipenem, carbenicillin, piperacillin, aztreonam, ticracillin, levofloxacin, ticarcillin, colistin, cefepime, and piperacillin. The reason for showing sensitivity against most of the antibiotics may rely on the fact that J. melonis is less reported from clinical samples and therefore might have been less exposed to the antibiotics but having appropriate genetic machinery may develop antibiotic resistance in this microbe on exposure to various clinical environments in the future.

Looking at the pathogenic role of microbes of this genus, we first time report the antibiotic susceptibilities exhibited by J. melonis CD11-4 so that it's further reports from clinical samples can be managed to improve patient's health.

On the other hand, J. terrae NBRC $107853^{\mathrm{T}}$ had one unique gene in subsystems cobalt-zinc-cadmium resistance, copper homeostasis, and mercury resistance operon that is not of clinical relevance. J. limosus NBRC $16128^{\mathrm{T}}$ had two unique genes for copper homeostasis and a gene for resistance to chromium compounds. Genomic profile of antibiotic resistance is suggestive of it's intestinal origin because food and human gut are reservoirs of antibiotic resistant genes [24, 25]. Thus, presence of several antibiotic resistance genes and unique genes in this category suggests the evolutionary transition of microorganisms into a gut pathogen.

Invasion and intracellular resistance Janibacter melonis CD11-4 contains operon systems that are known

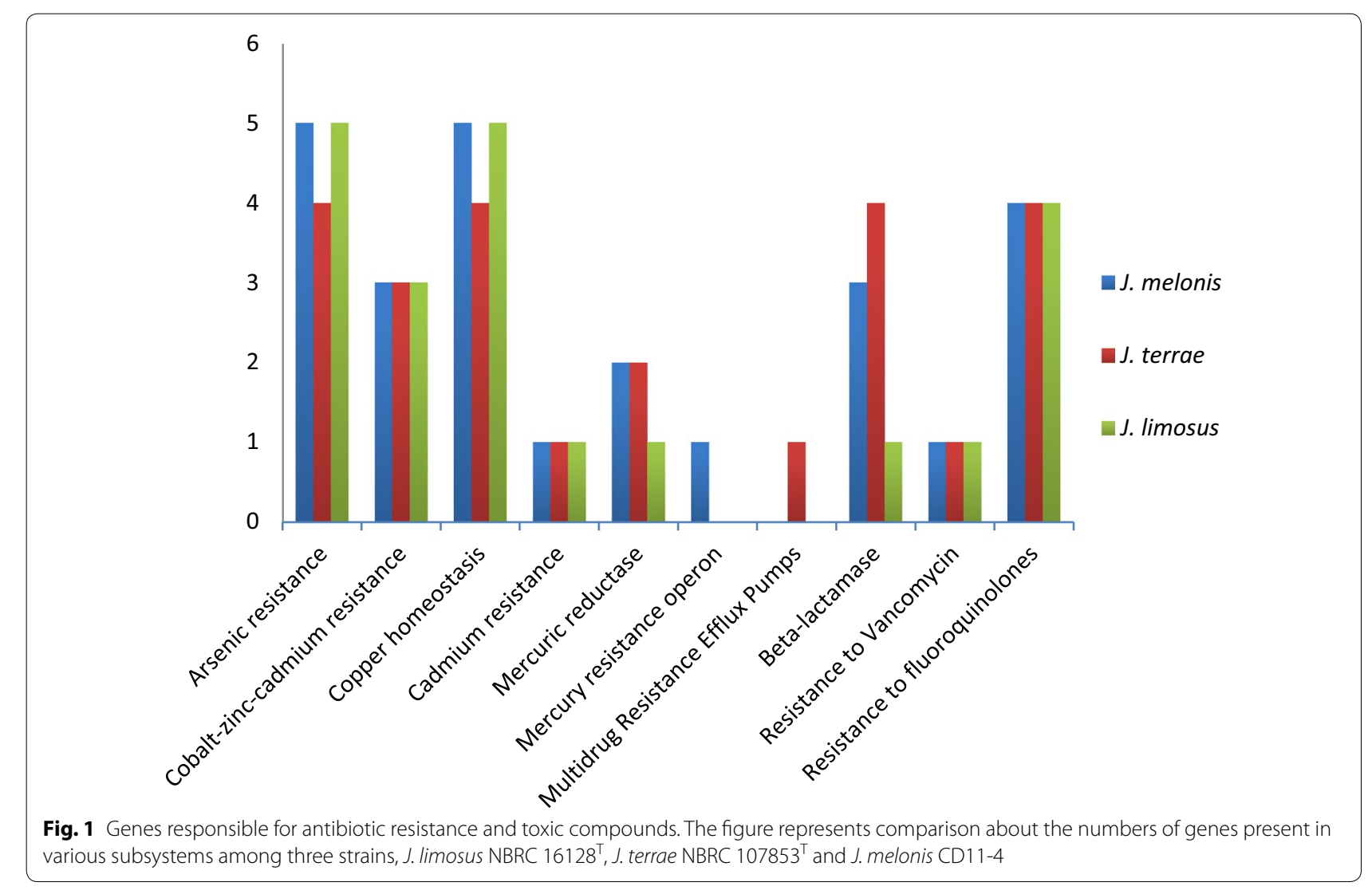


for virulence and invasion in Mycobacteria. In this subcategory, J. melonis CD11-4 had same set of 15 genes like J. terrae NBRC $107853^{\mathrm{T}}$. Two genes were present in subsystem Mycobacterium virulence operon involved in DNA transcription, 3 genes in Mycobacterium virulence operon involved in an unknown function with a Jag Protein and YidC and YidD, 3 genes in Mycobacterium virulence operon involved in protein synthesis (LSU ribosomal proteins), 4 genes in Mycobacterium virulence operon involved in protein synthesis (SSU ribosomal proteins), and 3 genes in subsystem Mycobacterium virulence operon possibly involved in quinolinate biosynthesis.

Two genes of subsystem Mycobacterium virulence operon involved in an unknown function with a jag protein and YidC and YidD were absent in J. limosus NBRC $16128^{\mathrm{T}}$ that were otherwise common in other two strains. One of these genes coded for inner membrane protein translocase component YidC and the other gene coded for protein YidD.

Other virulence factor genes Attributed to other potential virulence determinant genes, CD11-4 has some important genes that are also common in other members of the genus. In a subcategory, Programmed Cell Death and Toxin-Antitoxin Systems belonging to category, Regulation and Cell signaling, a gene coding for possible toxin to DivIC and another gene coding for a cell division protein DivIC (FtsB) that stabilizes FtsL against RasP cleavage was present. Such genes may activate under stress conditions to promote growth arrest, dormancy, and biofilm formation [28]. Interestingly, these genes were absent in $J$. terrae NBRC $107853^{\mathrm{T}}$.

In category Regulation and Cell signaling, J. melonis CD11-4 had 2 genes in the subsystem Stringent Response for (p)ppGpp metabolism. These genes regulate the global expression and activity of many virulence regulators in response to the stress (nutrient starvation) exerted in host microenvironment. GTP pyrophosphokinase (p)ppGpp synthetase II and guanosine- $3^{\prime}, 5^{\prime}$ bis(diphosphate) $3^{\prime}$-pyrophosphohydrolase are the two genes with above said roles that are also referred to as nucleotide alarmones due to their involvement in activating global signaling networks of virulence genes [29]. Like $J$. melonis, both the genes were also present in J. terrae NBRC $107853^{\mathrm{T}}$ whereas J. limosus NBRC $16128^{\mathrm{T}}$ lacked the gene coding for guanosine- $3^{\prime}, 5^{\prime}$-bis(diphosphate) $3^{\prime}$-pyrophosphohydrolase. Most of the dreaded pathogens rely on nucleotide alarmones to counteract the stressful conditions arose due to immune responses, changes in nutrient supply or while adhering new surfaces [30].

In addition, utilization of sialic acid by Vibrio cholera (an enteric pathogen) promotes it's colonization in gut
[31]. Sialic acid utilization pathway is crucial for infection of $V$. cholera in human gut. We reported that J. melonis CD11-4 had genes coding for 7 enzymes that can metabolize sialic acids. These genes code for enzymes, glucosamine-1-phosphate $N$-acetyltransferase, glucosamine-fructose-6-phosphate aminotransferase, phosphoglucosamine mutase, $\mathrm{N}$-acetylglucosamine-1-phosphate uridyltransferase, $\quad \mathrm{N}$-acetylglucosamine-6-phosphate deacetylase, UDP- $N$-acetylglucosamine 2-epimerase and sialic acid utilization regulator. Such genes were also present in J. terrae NBRC $107853^{\mathrm{T}}$ but absent in J. limosus NBRC $16128^{\mathrm{T}}$.

Janibacter melonis CD11-4 had 15 genes in subcategory oxidative stress. Out of these genes, 2 were coding for enzyme peroxidase and catalase to cope with the reactive oxygen species produced by human immune cells in an inflamed gut $[26,27]$. Thus the presence of such genes may enable these microbes to escape from human immune cells around the leaky intestines in inflammatory diseases like CD [16]. Such genes are not only suggestive for the possible role of strain CD11-4 in CD but are also indicative to propose it as a gut pathogen [16]. Based on the above-mentioned genetic repertoire possessed by $J$. melonis CD11-4, it may be categorized as a gut pathogen.

In addition, inside the host, efficient uptake of iron is an important factor for survival of pathogens [32]. Several opportunistic pathogens possess such genes in their genomes [33]. Presence of potential genes for iron uptake may further add adaptability and virulence property in $J$. melonis CD11-4. J. melonis CD11-4 had 5 genes in category iron acquisition and metabolism. EfeUOB system of genes present in J. melonis CD11-4 are meant for highaffinity uptake of iron in Bacillus subtilis [34]. Two genes in the subsystem $A B C$ transporters were also present that may promote $\mathrm{ABC}$ transporter-mediated uptake of iron. The genes of this category are also known to be responsible for inflammation and thus may have some role in pathogenesis of CD [16].

Infections are important factors in pathogenesis of $\mathrm{CD}$ and other autoimmune disorders. The above discussed genes in various gene categories Resistance to antibiotics and toxic compounds, Invasion and intracellular resistance, Oxidative stress, Iron acquisition system and Regulation and cell signaling are suggestive of virulent role of J. melonis CD11-4 in pathogenesis of CD.

\section{BRIG analysis}

BRIG software, that works based on BLAST, was used to create a circular comparative map of whole genome. Darker areas of rings represent the $100 \%$ sequence similarity with the genome considered as reference (J. limosus NBRC $16128^{\mathrm{T}}$ ), but the lighter (grey) areas represent $50 \%$ sequence similarity or less. Upper and lower thresholds 
for sequence identity were set as 70 and $50 \%$ subsequently. Genomes of $J$. spp. HTCC 2649 and J. melonis CD11-4 are showing maximum light bands representing more genetic variability while comparing with the reference genome of genus (J. limosus NBRC $16128^{\mathrm{T}}$ ) (Fig. 2).

\section{Future directions}

Considering the clinical importance of J. melonis, prevalence of these microbes need to be evaluated in the $C D$ patients and in other inflammatory disorders of gastrointestinal track validated by respective disease models.

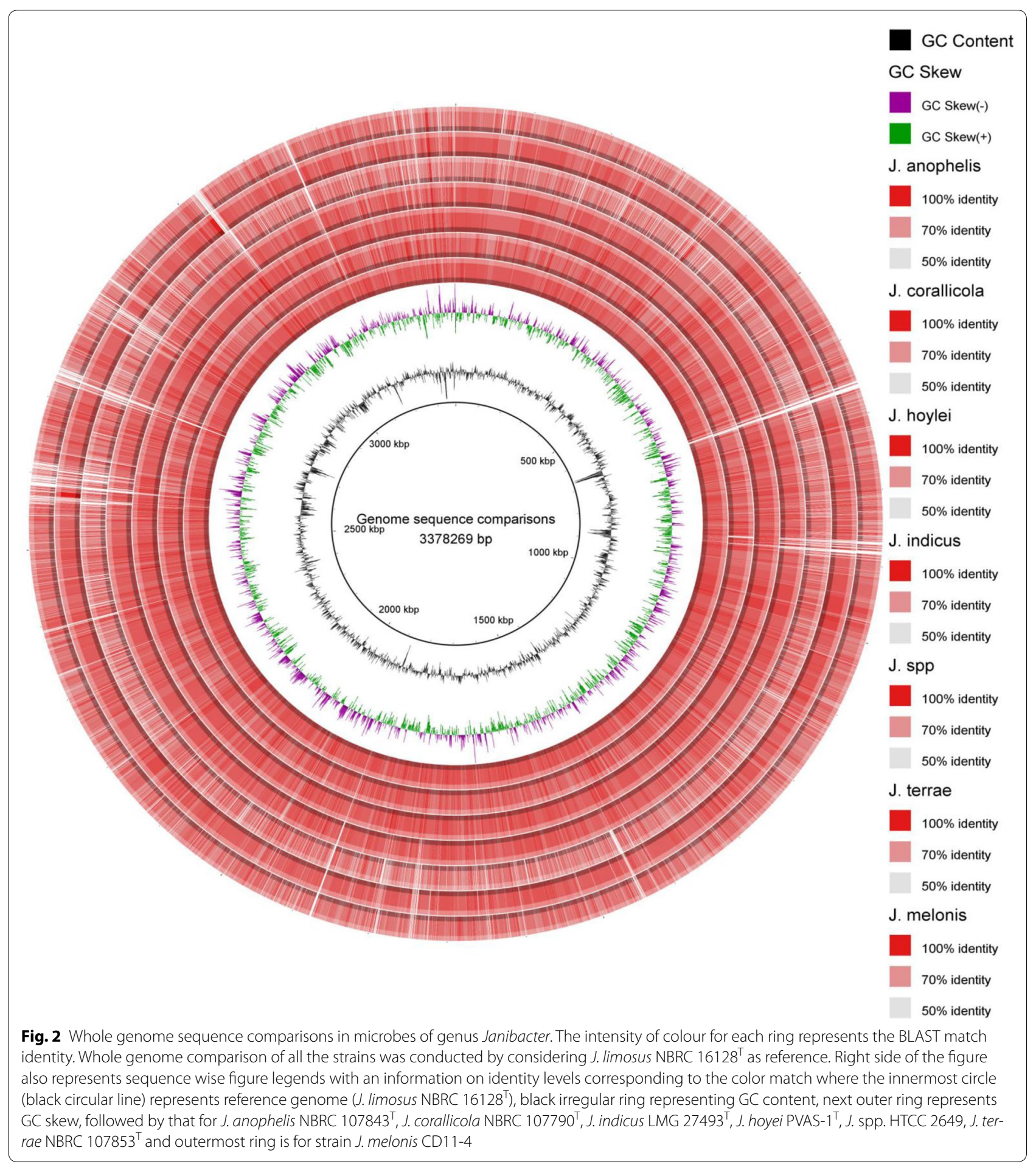


Moreover, this report will highlight that the infections of J. melonis in humans may need to be cured for improving clinical condition of patients presenting gastrointestinal symptoms/diseases.

\author{
Abbreviations \\ ANI: Average Nucleotide Identity; BRIG: BLAST Ring Image Generator; CD: \\ celiac disease; PBS: phosphate saline; RAST: Rapid Annotation Server and \\ Technology.
}

\section{Authors' contributions}

SM, SKB and AMC proposed this work. AMC collected samples, performed experiments, analyzed data, wrote first draft of manuscript. RK and SKB diagnosed patient, and RK provided biopsy samples during endoscopy. SM, SKB, DKD reviewed and edited manuscript. DKD and SM has critically edited the revised version of manuscript. Funds for research work were arranged by SM. All authors read and approved the final manuscript.

\begin{abstract}
Author details
${ }^{1}$ Department of Biophysics, Panjab University, Chandigarh, India. ${ }^{2}$ Department of Gastroenterology, Postgraduate Institute of Medical Education and Research, Chandigarh, India. ${ }^{3}$ Department of Endocrinology, Postgraduate Institute of Medical Education and Research, Chandigarh, India. ${ }^{4}$ Microbial Type Culture Collection and Gene Bank (MTCC), CSIR-Institute of Microbial Technology, Chandigarh 160036, India.
\end{abstract}

\section{Acknowledgements}

We are thankful to C-CAMP (http://www.ccamp.res.in/) next generation genomics facility for help in obtaining genome sequences.

\section{Competing interests}

The authors declare that they have no competing interests.

\section{Availability of data and materials}

The genome sequence of Janibacter melonis CD11-4 has been deposited in DDBJ/EMBL/GenBank under project Accession Number LQZG00000000. The version described in work is the first version, LQZG00000000.1.

\section{Consent for publication}

The participant has provided consent for publication of the research outcomes.

\section{Ethics approval and consent to participate}

The work in this publication was part of a large project which was approved by Institute Ethics Committee of Postgraduate Institute of Medical Education and Research, Chandigarh, India. Participants have provided an informed written consent to participate in this study.

\section{Funding}

We are grateful to Council of Scientific and Industrial Research, New Delhi, India for funding network project "Man as a Super organism: Understanding the Human Microbiome [BSC01 19] and partly supported by a project, "Expansion and Modernization of Microbial Type Culture Collection and Gene Bank (MTCC)," jointly supported by the Council of Scientific and Industrial Research (CSIR) Grant No. BSC0402 and Department of Biotechnology (DBT) Govt. of India Grant No. BT/PR7368/INF/22/177/2012. AMC, Senior Research Fellow is grateful to Indian Council of Medical Research, New Delhi, India for fellowship.

\section{Publisher's Note}

Springer Nature remains neutral with regard to jurisdictional claims in published maps and institutional affiliations.

Received: 14 November 2017 Accepted: 6 January 2018

Published online: 22 January 2018

\section{References}

1. Martin K, Schumann P, Rainey FA, Schuetze B, Groth I. Janibacter limosus gen. nov., sp. nov., a new actinomycete with meso-diaminopimelic acid in the cell wall. Int J Syst Bacteriol. 1997;47:529-34.

2. Fernández-Natal M, Sáez-Nieto J, Medina-Pascual M, Valdezate-Ramos S, Guerra-Laso J, Rodríguez-Pollán R, et al. First report of bacteremia by Janibacter terrae in humans. Infection. 2015:43:103-6.

3. Yoon J-H, Lee HB, Yeo S-H, Choi J-E. Janibacter melonis sp. nov., isolated from abnormally spoiled oriental melon in Korea. Int J Syst Evol Microbiol. 2004;54:1975-80

4. Elsayed S, Zhang K. Bacteremia caused by Janibacter melonis. J Clin Microbiol. 2005:43:3537-9.

5. Rastogi A, Bhadada SK, Bhansali A, Kochhar R, Santosh R. Celiac disease: a missed cause of metabolic bone disease. Indian J Endocrinol Metab. 2012;16:780-5.

6. Bhadada SK, Kochhar R, Bhansali A, Dutta U, Kumar PR, Poornachandra KS, et al. Prevalence and clinical profile of celiac disease in type 1 diabetes mellitus in north India. J Gastroenterol Hepatol. 2011;26:378-81.

7. Bhadada SK, Bhansali A, Ravikumar P, Kochhar R, Nain CK, Dutta P, et al. Changing scenario in aetiological profile of short stature in India-growing importance of celiac disease: a study from tertiary care centre. Indian J Pediatr. 2011;78:41-4.

8. Bhadada SK, Rastogi A, Agarwal A, Kochhar R, Kochhar R, Bhansali A. Comparative study of clinical features of patients with celiac disease \& those with concurrent celiac disease \& type 1 diabetes mellitus. Indian 」 Med Res. 2017;145:334-8.

9. Pozo-Rubio T, de Palma G, Mujico JR, Olivares M, Marcos A, Acuna MD, et al. Influence of early environmental factors on lymphocyte subsets and gut microbiota in infants at risk of celiac disease; the PROFICEL study. Nutr Hosp. 2013;28:464-73

10. Wacklin P, Laurikka P, Lindfors K, Collin P, Salmi T, Lahdeaho ML, et al. Altered duodenal microbiota composition in celiac disease patients suffering from persistent symptoms on a long-term gluten-free diet. Am J Gastroenterol. 2014;109:1933-41.

11. Cinova J, De Palma G, Stepankova R, Kofronova O, Kverka M, Sanz Y, et al. Role of intestinal bacteria in gliadin-induced changes in intestinal mucosa: study in germ-free rats. PLoS ONE. 2011;6:e16169.

12. Canova C, Zabeo V, Pitter G, Romor P, Baldovin T, Zanotti R, et al. Association of maternal education, early infections, and antibiotic use with celiac disease: a population-based birth cohort study in northeastern Italy. Am J Epidemiol. 2014;180:76-85.

13. Shmidt E, Smyrk TC, Boswell CL, Enders FT, Oxentenko AS. Increasing duodenal intraepithelial lymphocytosis found at upper endoscopy: time trends and associations. Gastrointest Endosc. 2014:80:105-11.

14. Chander AM, Kaur G, Nair RG, Dhawan DK, Kochhar R, Mayilraj S, et al. Genome sequencing of Serinicoccus chungangensis strain CD08 5 isolated from duodenal mucosa of a celiac disease patient. Genome Announc. 2016:4:e00043-16.

15. Chander AM, Nair RG, Kaur G, Kochhar R, Mayilraj S, Dhawan DK, et al. Genome sequence of Kocuria palustris strain CD07_3 isolated from the duodenal mucosa of a celiac disease patient. Genome Announc. 2016;4:e00210-16.

16. Chander AM, Nair RG, Kaur G, Kochhar R, Dhawan DK, Bhadada SK, et al. Genome insight and comparative pathogenomic analysis of Nesterenkonia jeotgali strain CD08_7 isolated from duodenal mucosa of celiac disease patient. Front Microbiol. 2017;8:129.

17. Mayilraj S, Saha P, Suresh K, Saini HS. Ornithinimicrobium kibberense sp. nov., isolated from the Indian Himalayas. Int J Syst Evol Microbiol. 2006;56:1657-61.

18. Aziz RK, Bartels D, Best AA, DeJongh M, Disz T, Edwards RA, et al. The RAST server: rapid annotations using subsystems technology. BMC Genom. 2008;9:75.

19. Overbeek R, Olson R, Pusch GD, Olsen GJ, Davis JJ, Disz T, et al. The SEED and the rapid annotation of microbial genomes using subsystems technology (RAST). Nucleic Acids Res. 2014;42:D206-14.

20. Brettin T, Davis JJ, Disz T, Edwards RA, Gerdes S, Olsen GJ, et al. RASTtk: a modular and extensible implementation of the RAST algorithm for building custom annotation pipelines and annotating batches of genomes. Sci Rep. 2015;5:8365. 
21. Alikhan NF, Petty NK, Ben Zakour NL, Beatson SA. BLAST Ring Image Generator (BRIG): simple prokaryote genome comparisons. BMC Genom. 2011;12:402.

22. Lee I, Kim YO, Park S-C, Chun J. OrthoANI: an improved algorithm and software for calculating average nucleotide identity. Int J Syst Evol Microbiol. 2016;66:1100-3.

23. Yoon S-H, Ha S-M, Lim J, Kwon S, Chun J. A large-scale evaluation of algorithms to calculate average nucleotide identity. Antonie van Leeuwenhoek. 2017;110:1281-6.

24. Rolain J-M. Food and human gut as reservoirs of transferable antibiotic resistance encoding genes. Front Microbiol. 2013:4:173.

25. Burmeister AR. Horizontal gene transfer. Evol Med Public Health. 2015;2015:193-4

26. Paiva CN, Bozza MT. Are reactive oxygen species always detrimental to pathogens? Antioxid Redox Signal. 2014;20:1000-37.

27. Stoiber W, Obermayer A, Steinbacher P, Krautgartner WD. The role of reactive oxygen species (ROS) in the formation of extracellular traps (ETs) in humans. Biomolecules. 2015;5:702-23.
28. Page R, Peti W. Toxin-antitoxin systems: novel mechanisms of toxin activity and antitoxin inhibition. FASEB J. 2017;31:111.111.

29. Hauryliuk V, Atkinson GC, Murakami KS, Tenson T, Gerdes K. Recent functional insights into the role of (p) ppGpp in bacterial physiology. Nat Rev Microbiol. 2015;13:298.

30. Dalebroux ZD, Svensson SL, Gaynor EC, Swanson MS. ppGpp conjures bacterial virulence. Microbiol Mol Biol Rev. 2010;74:171-99.

31. Rohmer L, Hocquet D, Miller SI. Are pathogenic bacteria just looking for food? Metabolism and microbial pathogenesis. Trends Microbiol. 2011;19:341-8.

32. Wooldridge KG, Williams PH. Iron uptake mechanisms of pathogenic bacteria. FEMS Microbiol Rev. 1993;12:325-48.

33. Manfredi P, Lauber F, Renzi F, Hack K, Hess E, Cornelis GR. New iron acquisition system in Bacteroidetes. Infect Immun. 2015;83:300-10.

34. Miethke M, Monteferrante CG, Marahiel MA, van Dijl JM. The Bacillus subtilis EfeUOB transporter is essential for high-affinity acquisition of ferrous and ferric iron. Biochim Biophys Acta. 2013;1833:2267-78.

\section{Submit your next manuscript to BioMed Central and we will help you at every step:}

- We accept pre-submission inquiries

- Our selector tool helps you to find the most relevant journal

- We provide round the clock customer support

- Convenient online submission

- Thorough peer review

- Inclusion in PubMed and all major indexing services

- Maximum visibility for your research

Submit your manuscript at www.biomedcentral.com/submit 